\title{
Inovar-auto: continuação ou ruptura da indústria dependente?
}

\author{
Tiago Bernardino Vargas ${ }^{1}$ \\ Geraldo Augusto Pinto ${ }^{2}$
}

\begin{abstract}
RESUMO
O Inovar-Auto foi um programa do governo do Partido dos Trabalhadores (PT), tendo na presidência executiva Dilma Rousseff (eleita em 2012), com o objetivo, definido na Lei 12.715 de 2012, de promover o desenvolvimento tecnológico no setor automotivo. Pela contemporaneidade do programa, as discussões científicas sobre seus resultados ainda estão em vigor, centradas no desenvolvimento da cadeia automotiva nacional e no atingimento de seu objetivo principal: desenvolvimento tecnológico. Este artigo objetiva discutir o programa tomando como base de análise a Teoria Marxista da Dependência (TMD). A partir de uma contextualização da industrialização e da indústria dependente, apresenta-se o caso particular da formação da indústria automotiva brasileira. Desse contexto, reflete-se sobre o Inovar-Auto como uma continuação ou uma ruptura de categorias características da indústria dependente. Conclui-se que o programa manteve, de modo geral, um favorecimento às multinacionais e a manutenção do padrão de importação tecnológica, que evidencia a continuidade das estruturas da dependência. Porém, houve uma inovação que aponta para uma ruptura do padrão de dependência: diferente dos demais incentivos públicos históricos ao setor automotivo brasileiro, houve a inclusão do setor de ferramentaria como um favorecido indireto, um setor que mantem suas bases nacionais força de trabalho, engenharia e desenvolvimento nacionais.
\end{abstract}

Palavras-chave: Inovar-Auto. Indústria Automotiva. Políticas Industriais. Teoria Marxista da Dependência.

\section{INTRODUÇÃO}

Este artigo discute o Inovar-Auto, um programa governamental de incentivo à indústria automotiva brasileira, sob a ótica da Teoria Marxista da Dependência (TMD). Para tanto, caracterizar-se-á, primeiramente, a industrialização no modo de produção capitalista e as particularidades que assumiu na América Latina, ou seja, sob as determinações da economia dependente latino-americana.

Após, tratar-se-á do ramo da indústria em que o objeto se insere: o automotivo, com foco em sua constituição atual no Brasil. O intuito será sintetizar o histórico das políticas públicas de incentivo ao setor automotivo, desenvolvidas anteriormente ao Inovar-Auto desde sua instalação no Brasil e, a seguir, a emergência deste.

Assim, o objeto será contextualizado dentro das caracterizações elencadas: a indústria no modo de produção capitalista, a industrialização dependente latino-americana, a

\footnotetext{
${ }^{1}$ Programa de Pós-Graduação em Tecnologia e Sociedade (PPGTE), Universidade Tecnológica Federal do Paraná (UTFPR), tiagovargas@alunos.utfpr.edu.br.

${ }^{2}$ Programa de Pós-Graduação em Tecnologia e Sociedade (PPGTE), Universidade Tecnológica Federal do Paraná (UTFPR), geraldoaugustopinto@gmail.com.
} 
indústria automotiva brasileira e, por fim, os programas governamentais de incentivo a esse, com foco no Inovar-Auto. Por fim, relaciona-se o programa com as categorias da TMD, apontando contradições e acertos que representam ora uma continuação da dependência, ora uma ruptura.

\section{A INDUSTRIALIZAÇÃO E A INDÚSTRIA DEPENDENTE}

Iniciando pelo papel da indústria no modo de produção capitalista, tem-se que ela se origina condicionada pelos mecanismos da acumulação capitalista, ou melhor, a busca por taxas de lucro extraordinárias num ambiente concorrencial cada vez mais acirrado. E se caracteriza também pela formação da classe trabalhadora, classe social que resiste ao processo de exploração de sua força de trabalho. A transformação na sociedade provocada pela industrialização é parte de um processo de acumulação capitalista e de formação de uma população destituída dos meios de produção. Outra caracterização das mutações da industrialização são as modificações técnicas, restritas e orientadas pelo seu contexto histórico, que emergiram satisfazendo as necessidades do modo de produção capitalista de reproduzir-se de forma ampliada, explorando o trabalho (Dobb, 1986; Marx, 2013).

Destacam-se, portanto, três elementos constituintes da industrialização: há uma acumulação capitalista prévia motivada por maiores taxas de lucro de uma classe (classe proprietária dos meios de produção); há uma população de destituídos, desprovidos de meios de subsistência e coagidos a vender sua força de trabalho; e, há um processo de modificações técnicas direcionadas para os interesses dos proprietários dos meios de produção.

Este processo de industrialização ocorre, primeiramente, entre os séculos XVIII e XIX, nos países centrais, tendo à frente a Inglaterra, enquanto regiões periféricas, como a América Latina, inseriram-se em tal movimento fornecendo produtos primários, isto é, agrícolas, pecuários e minerais. Posteriormente, já na primeira metade do século $\mathrm{XX}$, o poder das transformações da industrialização teve como efeito uma concentração de capital, que resultou em colapsos econômicos que criaram obstáculos à reprodução do próprio modo de produção capitalista. Uma das formas encontradas pelo capital de continuar sua expansão em momentos de crise foi através da difusão de ramos industriais nos países periféricos (Fernandes, 2009).

Antes disso, porém, é necessário ater-se ao fato de que o relacionamento dos países periféricos com os países centrais, desde o processo de industrialização destes últimos, 
foi caracterizado pela divisão internacional do trabalho. Em outros termos, com a eclosão da industrialização, houve uma divisão em países produtores primários e produtores industriais. Advogava-se que o desenvolvimento do comércio internacional teria vantagens a todos. No entanto, o resultado foi uma troca desigual: os países produtores primários viram seus produtos desvalorizarem progressivamente em relação aos produtos industrializados, criando distorções entre o desenvolvimento dos países centrais e os periféricos (Prebisch, 2012).

A Teoria Marxista da Dependência (TMD) demonstra que o desenvolvimento nos países centrais só foi possível graças ao subdesenvolvimento dos países periféricos e dependentes, tal como os latino-americanos. Os países dependentes eram responsáveis pelo suprimento de matérias primas e produtos alimentícios a baixo custo, mediante a superexploração da força de trabalho na região (Marini, 2011).

O conceito de superexploração da força de trabalho, criado por Marini (2011), refere-se a um mecanismo que, embora tendencial na reprodução do capital como um todo, adquire um caráter estrutural no capitalismo periférico, devido ao intercâmbio desigual. Quer dizer, para compensar a contínua queda dos preços dos produtos primários em relação aos produtos industrializados, os capitais investidos nos países dependentes se apropriaram de uma exploração da força de trabalho peculiar: o capital remunera o trabalhador em valor inferior ao necessário à reprodução de sua força de trabalho.

A especialização da economia dependente em exportadora primária, com características peculiares tais como a superexploração da força de trabalho, condicionou seu desenvolvimento industrial. A demanda da classe proprietária dos meios de produção ligada aos setores primários exportadores, somada à de parte da classe trabalhadora local (ainda que o assalariamento fosse incipiente), fomentaram o surgimento de uma indústria nacional inicial, com produção de mercadorias de baixo custo. Este desenvolvimento industrial ocorreu como política de substituição das importações, nos momentos de dificuldade de importação devido as crises e guerras das economias centrais. A industrialização aconteceu através da importação de máquinas e, inicialmente, na produção de bens de consumo leves; passa posteriormente aos bens de consumo duráveis; depois, bens de consumo intermediários e, por fim, bens de produção pesados (Bambirra, 2013).

Em sintonia com o papel da industrialização no modo de produção capitalista, se observa, nos primeiros desenvolvimentos industriais na América Latina, uma acumulação capitalista prévia, a formação de uma população de destituídos dos meios de produção, empurrados ao assalariamento, e um processo de modificações técnicas. 
Entretanto, há algumas particularidades na industrialização dependente. Uma em saliência é a classe proprietária dos meios de produção dos países periféricos e sua motivação pela extrema exploração do trabalho. O fato é que, ao mesmo tempo em que depende da realização de seus produtos no mercado internacional e, por meio do mecanismo de transferência de valor, tem suas taxas de lucros continuamente rebaixadas, tal classe proprietária acaba por impor à classe trabalhadora local uma superexploração de sua força de trabalho. Por outro lado, o burguês exportador da economia dependente nasce da classe oligárquica, não criando uma cisão com os meios de produção anterior: há uma superação lenta e descontínua, passando "de uma formação socioeconômica dependente colonialexportadora para uma formação socioeconômica dependente capitalista-exportadora, até finalmente chegar uma formação socioeconômica dependente capitalista-industrial" (Bambirra, 2013, p. 78). Por fim, cabe frisar a questão da tecnologia, que, embora necessária para a industrialização dos países periféricos, aconteceu em bases distintas: através da importação de máquinas e tecnologias dos países centrais.

Este processo de industrialização por substituição de importações ocorreu lentamente, mas criou as bases necessárias para um desenvolvimento industrial efetivo que ocorreria no pós-guerra, a partir da década de 1940. Neste período, os países dependentes se tornam atrativos para o capital estrangeiro, pois oferecem: possibilidades sedutoras de lucro com sua superexploração da força de trabalho; expansão para novos mercados; e possibilidade de exportação de maquinários obsoletos. Isto é, no momento em que países latino-americanos buscaram tecnologia e capital para sua industrialização, as multinacionais dos países centrais se dirigiram a eles (Marini, 2011).

As frações burguesas ligadas à atividade industrial que se formavam localmente não foram capazes de confrontar o capital internacional entrante, sendo relegadas à condição de sócias menores do capital internacional, "levando-as a abandonar suas perspectivas de independência nacional e pretensões de desenvolvimento tecnológico próprio" (Dos Santos, 2015, p. 84). O processo de industrialização destes países dependentes ocorreu, portanto, como resultado da expansão do capital dos países centrais, com a ascensão ao poder da classe proprietária dos meios de produção industrial dependente, se prostrando diante do capital internacional em expansão, minimizando seu desenvolvimento autóctone.

Logo, os aspectos característicos da industrialização dependente são: a manutenção de uma particular disparidade entre o capital e o trabalho, assegurando que a condição de investimento do capital estrangeiro em tais economias se mantenha baseada na 
superexploração da força de trabalho; a importação de tecnologias amortizadas em seus países de origem; e, a ascensão de uma classe proprietária dos meios de produção industrial local oriunda da oligarquia que se coliga ao capital estrangeiro.

\section{A INDÚSTRIA AUTOMOTIVA BRASILEIRA}

Uma experiência específica deste desenvolvimento industrial em países dependentes foi a do setor automotivo brasileiro. Até a década de 1920, os veículos em território nacional eram majoritariamente importados. Neste mesmo período, se instalaram no país montadoras de kits completos (Completely Knocked Down-CKD). Em outros termos, os veículos eram importados parcialmente montados, efetuando-se localmente uma montagem final. Nos períodos de crise (como em 1929) e guerra (como entre 1914-1919 e entre 19391945) dos países centrais, desenvolveu-se uma cadeia de indústria de peças automotivas no Brasil, focadas inicialmente no mercado de reposição. Ainda assim, mesmo contando com uma rede de produtores de peças locais, na década de 1940, produtos automotivos eram os itens de maior importação no Brasil, ultrapassando petróleo e trigo (Shapiro, 1997).

Essa elevada importação afetava o balanço de pagamentos nacional, o que levou o governo a restringir importações de itens que já possuíam produção local. No entanto, o grande incentivo à industrialização brasileira ocorreu na década de 1950, no governo do presidente Juscelino Kubitschek (1956-1961), com a restrição (em nível proibitivo) à importação de veículos e o incentivo à instalação de fábricas. A necessidade de expansão das empresas estrangeiras, somada ao potencial de crescimento do mercado brasileiro resultou na industrialização do setor nacionalmente. Foram enviados ao Brasil equipamentos e máquinas dos países de origem das empresas, sendo que, em alguns casos como o da GM estadunidense, eram explicitamente obsoletos (Shapiro, 1997).

O setor de autopeças, que havia se desenvolvido anteriormente à vinda das montadoras estrangeiras, se beneficiou da expansão industrial do período, apoiado pelos incentivos estatais. $\mathrm{O}$ plano governamental incluía, entre suas exigências, percentuais mínimos de conteúdo local. O fruto foi que, em 1961, os veículos produzidos nacionalmente tinham alcançado a meta de $95 \%$ de conteúdo nacional imposto pelo governo (Addis, 1997).

Observa-se que esse início de desenvolvimento da indústria automotiva à luz da Teoria Marxista da Dependência se atém às características da industrialização no modo capitalista. Evidenciando-se alguns elementos, tem-se: o prévio desenvolvimento industrial 
por substituição de importações antes da década de 1940; o nascimento da classe proprietária dos meios de produção industrial nacional durante este período e que posteriormente se renderá ao capital estrangeiro (venda das empresas nacionais para as multinacionais); a importação de tecnologias obsoletas; e, a existência de uma população carente que se formou como classe trabalhadora.

A partir de 1990, inicia-se uma mudança estrutural na economia brasileira, com abertura comercial, desregulamentação e privatizações. A reforma tarifária do período traduz a abertura comercial: a tarifa média de importação de veículos passa de $41 \%$ em 1988, para 12,6\% em 1996 (Comin, 1998).

Reagindo ao aumento de importações, governo, empresas e trabalhadores do setor automotivo estabeleceram acordos para incentivar a indústria nacional - foram realizados dois acordos setoriais, em 1992 e 1993. Ambos os acordos tinham como objetivo a redução do preço do produto, através do esforço compartilhado entre Estado e empresas: redução tarifária; redução das margens de lucro das montadoras; e, redução das margens de lucro das concessionárias. Além disto, foram acordadas questões relativas ao emprego e salários do setor. Os acordos tiveram o mérito de reverter a desindustrialização e representaram um destaque em seu aspecto democrático de envolvimento dos trabalhadores junto as negociações setoriais (Comin, 1998).

Porém, o consenso entre os atores não perdurou, devido a uma nova postura governamental de negociação direta com as empresas, ou mesmo, sem qualquer negociação. Iniciando pela promulgação do protocolo do carro popular ${ }^{3}$, as novas políticas decididas unilateralmente aumentavam os conflitos do setor ${ }^{4}$. Esta situação de disputa foi amenizada em 1995, com a nova política industrial do governo do presidente Fernando Henrique Cardoso (1995-2002), o Regime Automotivo Brasileiro (RAB).

O RAB se assemelhava ao regime automotivo argentino já vigente e propunha reduções tributárias condicionadas a exigências, tal como níveis mínimos de conteúdo local e percentuais de investimento e exportação. Os incentivos eram focalizados nas montadoras (estrangeiras). Como resultado, o regime provocou uma reindustrialização com

\footnotetext{
${ }^{3}$ O protocolo do carro popular criou, em 1990, uma nova faixa de incidência de IPI para veículos até 1000 cilindradas, nominados de carro popular. A nova categoria recebia o benefício de uma redução drástica do IPI, passando a ser tributado em uma alíquota simbólica de $0,1 \%$.

${ }^{4}$ Exemplo de embate foi em 1995, quando o governo propôs um aumento de carga tributária para o setor e aumentou os desentendimentos dos atores: montadoras discordaram publicamente do governo; trabalhadores foram contrários ao aumento de preço dos populares; e, a reação dos consumidores também foi negativa. O episódio evidenciou que a área econômica impunha ao setor novas regras, desconsiderando negociações prévias ou em curso (COMIN, 1998).
} 
desnacionalização: expansão das instalações no país, com ampliação da produção, vendas, exportações, importações e investimentos. Tal crescimento acompanhou o crescimento do mercado interno (Torres, 2011).

Após o RAB, os incentivos ao setor automotivo foram pontuais, como ações anticíclicas após a crise de 2008, através de isenções tributárias sem contrapartidas exigidas pelo governo. Um novo regime ao setor seria formulado apenas em 2012, o Inovar-Auto. O Inovar-Auto diferiu do $\mathrm{RAB}$ em seu objetivo. $\mathrm{O}$ RAB objetivava novos investimentos e expansão do setor, ou melhor, aumento de produção e exportação. Já o Inovar-Auto, visava o desenvolvimento tecnológico, inovação e sustentabilidade. Estes três elementos advinham da política industrial que o Inovar-Auto fazia parte, o Plano Brasil Maior (PBM).

\section{O INOVAR-AUTO}

O Inovar-Auto se iniciou sob o governo do Partido dos Trabalhadores (PT), no primeiro mandato de Dilma Rousseff na Presidência da República (eleita em 2012 e impedida no cargo em 2016). O programa se encerrou em 2017 e teve como objetivo declarado promover o desenvolvimento tecnológico no setor automotivo. A Lei 12.715/2012 assim o descreve:

Fica criado o Programa de Incentivo à Inovação Tecnológica e Adensamento da Cadeia Produtiva de Veículos Automotores - INOVAR-AUTO com objetivo de apoiar o desenvolvimento tecnológico, a inovação, a segurança, a proteção ao meio ambiente, a eficiência energética e a qualidade dos automóveis, caminhões, ônibus e autopeças (BRASIL, 2012a, p. 4).

O incentivo destinou-se a três modalidades de empresas: aquelas que fabricam em território nacional os produtos abrangidos pelo programa (em síntese, automóveis, caminhões e ônibus); as que possuem projetos de novas plantas industriais para fabricação dos mesmos; e as que comercializam os produtos no país (Brasil, 2012a).

Para se habilitar ao programa as empresas deveriam cumprir dois requisitos obrigatórios e três requisitos opcionais. Os requisitos obrigatórios eram o cumprimento de metas de eficiência de consumo de combustível e a manutenção de situação regular em relação aos tributos federais.

Quanto aos requisitos opcionais, as empresas poderiam escolher quais elas cumpririam. No caso de montadoras, deveriam escolher três de quatro, que eram: número mínimo de percentual de nacionalização das peças e operações; percentual do faturamento em 
dispêndios em pesquisa e desenvolvimento; percentual do faturamento em dispêndios em engenharia, tecnologia e fornecedores; e, participação no programa Etiquetagem $\operatorname{Veicular}^{5}$ (Brasil, 2012b).

As empresas habilitadas receberam benefício tributário em forma de crédito de IPI (Impostos sobre Produtos Industrializados), apurados pela compra de insumos estratégicos e ferramentaria, majoritariamente.

Em síntese, o Inovar-Auto objetivava atuar, em sua literalidade legislativa, nas mudanças técnicas. Para tanto, ele beneficia um ramo industrial, as montadoras automotivas, e seus fornecedores indiretamente.

\section{CONSIDERAÇÕES SEGUNDO A TMD}

Ao contextualizar o processo de industrialização nos países centrais, evidenciouse que esse ocorreu pela formação de uma classe de possuidores de meio de produção, uma de possuidores de força de trabalho e de modificações técnicas. A partir desse enfoque, introduziu-se a industrialização dependente que discute a formação desses elementos nos países periféricos, em condições particulares: com uma superexploração da força de trabalho, a importação das modificações técnicas e uma classe de proprietários de meios de produção locais submissos ao capital estrangeiro.

Nessa conjuntura a indústria automotiva se desenvolveu no Brasil. Após uma série de incentivos estatais que motivou a vinda de multinacionais, o país se encontrava em 2012 com uma cadeia produtora de automóveis, cujas grandes empresas eram de capital estrangeiro, que importavam tecnologia de suas bases nos países centrais e produziam localmente. O Inovar-Auto foi promulgado propondo um desenvolvimento tecnológico local. Ele fornecia isenções tributárias às montadoras multinacionais mediante às condições que favoreciam este desenvolvimento tecnológico local.

Contudo, há indícios de que os requisitos de investimento em inovação e tecnologia não representavam uma dificuldade para as montadoras instaladas no país, tal como relatou um gerente de uma fornecedora de autopeças em 2014, que "os limites mínimos de dispêndios requeridos pelo programa já eram atingidos pela indústria antes de sua implantação" (Cunha, 2017, p. 50). A definição de tais requisitos pretendia apenas, nas

\footnotetext{
${ }^{5}$ O Programa Brasileiro de Etiquetagem Veicular, estabelecido pelo Instituto nacional de Metrologia, Qualidade e Tecnologia (INMETRO), classifica os veículos em faixas de desempenho, de acordo com sua categoria, motorização, acessórios e, principalmente, consumo de combustível.
} 
palavras do presidente da Associação Nacional dos Fabricantes de Veículos Automotores (ANFAVEA) em 2012, “que todas as empresas pudessem atingir” (Cunha, 2017, p. 50).

Outra questão do programa foi a omissão dos veículos híbridos e elétricos no seu início. Ou seja, ainda que o desenvolvimento tecnológico nacional tenha permeado a legislação do programa, ele apontava para uma mudança incremental das estruturas tecnológicas nacionais. Uma hipótese é que o programa tenha sido elaborado para beneficiar atores específicos da cadeia automotiva, com por exemplo, montadoras que já detinham os índices exigidos. De qualquer forma, estudos vincularam o programa às inovações incrementais e não disruptivas, por contrariar a tendência mundial de incentivo às tecnologias de veículos elétricos (Marx; Mello, 2014; Mesquita et al., 2013).

Aprofundando o debate em torno do desenvolvimento tecnológico, tem-se que o programa objetivou apenas alcançar as tecnologias estrangeiras para o modelo de mobilidade corrente. De outra maneira, o programa lidou apenas com o modelo de transporte e mobilidade vigente, sem incentivar novas perspetivas de soluções alternativas que resultem em redução dos tráfegos e uso do espaço urbano (Marx; Mello, 2014).

Relacionando este aspecto de desenvolvimento tecnológico do Inovar-Auto à característica da industrialização dependente de importação de tecnologias dos países centrais, os estudos apontam que as metas e condições impostas foram incapazes de romper com a dependência tecnológica, evidenciando que o programa tenha se caracterizado pela continuidade desta categoria central da indústria dependente através da importação de tecnologia das matrizes das multinacionais. Ademais, soma-se a essa continuidade o fato de que os atores beneficiados pelo programa foram as montadoras automotivas, todas de capital internacional. Isto é, o Estado brasileiro mantém a posição histórica de incentivar a vinda do capital estrangeiro como um pilar da industrialização nacional.

Todavia, o programa privilegiou outros atores indiretamente, fornecedores automotivos e ferramentarias nacionais. Quer dizer, para que as montadoras recebessem benefício tributário elas deveriam comprar insumos estratégicos.

Ocorre que dentro da noção de "estratégico" restou como critério apenas o fato de serem produtos fabricados nacionalmente. Isto é, deveriam comprar insumos produzidos localmente. Esta determinação ocasionou questionamento na Organização Mundial do Comércio (OMC), sob a alegação de que o programa violava acordos internacionais de comércio, privilegiando produtores nacionais (Cunha, 2017). 
Semelhante questionamento foi realizado para o RAB. Então, esta atuação da OMC permite indagar se os limites impostos aos programas de incentivo à indústria nos países dependentes atuam na manutenção de seu subdesenvolvimento (e dependência), inibindo a criação de uma indústria nacional competitiva (Schapiro, 2017).

Como fornecedores automotivos, há que se considerar a predominância de grandes empresas multinacionais, dentre os fornecedores de primeiro nível - fornecedores que produzem sistemas e componentes complexos (Pinto, 2011). Assim, mesmo que o InovarAuto previsse o incentivo à fornecedores locais, entende-se que haja uma predominância de capital estrangeiro também nos fornecedores.

No entanto, houve no programa a inclusão de um ator que não foi considerado nos programas anteriores de incentivo a indústria automotiva nacional: o setor de ferramentaria. A ferramentaria automotiva fabrica conjuntos de ferramentas ou dispositivos que são acopladas às máquinas para a produção de peças, que em geral são estampadas ou injetadas (Sakuramoto, 2002). Uma das formas de as montadoras obterem o benefício tributário era comprando ferramentas produzidas localmente.

Em vídeo de evento promovido em fevereiro de 2016 (um ano antes do término do Inovar-Auto) pelo Sindicato dos metalúrgicos do $\mathrm{ABC}$, o presidente da Associação da Indústria de Ferramenta (ABINFER) revela o otimismo do setor, que planejava a continuidade do programa em novas etapas, após o seu encerramento (Sindicato..., 2016). A indústria de ferramentas brasileira é um setor composto por muitas empresas de pequeno porte, que desempenham atividades complexas, com força de trabalho, engenharia e desenvolvimento tecnológico nacionais (Vargas, 2018). A peculiaridade do Inovar-Auto ter incluído a ferramentaria como um setor beneficiário, aponta para um rompimento de uma característica da indústria automotiva e de seu caráter dependente: a dependência histórica do setor na importação de ferramentas.

Logo, destaca-se que o Inovar-Auto, um incentivo tributário destinado a um setor que foi historicamente favorecido por políticas públicas, manteve o padrão presente na industrialização dependente de beneficiar multinacionais (capital estrangeiro) e importação de tecnologias. Em sua literalidade ele exigia um nível de desenvolvimento tecnológico local, mas as evidências apontam que este nível era baixo e facilmente alcançável pelas empresas participantes. Contudo, a inclusão do setor de ferramentaria representou um avanço nas políticas públicas do setor, por beneficiar, mesmo que indiretamente, um ramo de capital nacional, com desenvolvimento de engenharia e tecnologia local. 
Para trabalhos futuros, há que se investigar os efeitos práticos que o Inovar-Auto representou para o setor de ferramentaria, além de aprofundar o debate em torno das categorias da TMD e o Inovar-Auto.

\section{REFERÊNCIAS}

ADDIS, C. Cooperação e desenvolvimento no setor de autopeças. In: ARBIX, G.; ZILBOVICIUS, M. (Eds.). . De JK a FHC: a reinvenção dos carros. São Paulo: Scritta, 1997. p. 134-157.

BAMBIRRA, V. O capitalismo dependente latino-americano. 2. ed. Florianópolis: Insular, 2013.

BAZZO, W. et al. O que é ciência, tecnologia e sociedade? In: GALBARTE, I. VON LI.; PEREIRA, L. T. DO V. (Eds.). . Introdução aos Estudos CTS (Ciência, Tecnologia e Sociedade). Madrid: Organización de Estados Iberoamericanos (OEI), 2003. p. 119-156.

BRASIL. Lei n. 12.715, de 17 de setembro de 2012. Diário Oficial da União, 2012a.

BRASIL. Decreto n. 7.819, de 3 de outubro de 2012. Diário Oficial da União, 2012b.

COMIN, A. De volta para o futuro: política e reestruturação industrial do complexo automobilístico nos anos 90. FAPESP ed. São Paulo: Annablume, 1998.

CUNHA, R. D. Avaliação dos aspectos tributários do Inovar-Auto: programa de incentivos à indústria automotiva. Dissertação (mestrado) —São Paulo: Escola de Direito de São Paulo da Fundação Getúlio Vargas, 2017.

CUTCLIFFE, S. La emergencia de CTS como campo académico. In: Ideas, Maquinas y Valores. Barcelona: Anthropos, 2003.

DOBB, M. A evolução do capitalismo. Traducao Manuel do Rêgo Braga. 2. ed. São Paulo: Nova Cultural, 1986.

DOS SANTOS, T. Teoria da dependência: balanço e perspectivas. Florianópolis: Insular, 2015.

FERNANDES, F. Capitalismo dependente e classes sociais na América Latina. São Paulo: Global, 2009.

MARINI, R. M. Dialética da dependência, 1973. In: TRASPADINI, R.; STEDILE, J. P. (Eds.). . Ruy Mauro Marini: vida e obra. 2. ed. São Paulo: Expressão Popular, 2011. p. 131-172.

MARX, K. O Capital: crítica da economia política. Livro I: o processo de produção do capital. Traducao Rubens Enderle. São Paulo: Boitempo, 2013.

MARX, R.; MELLO, A. M. D. New initiatives, trends and dilemmas for the Brazilian automotive industry: the case of Inovar Auto and its impacts on electromobility in Brazil. International Journal of Automotive Technology and Management, v. 14, n. 2, p. 138, 2014.

MESQUITA, D. L. et al. Aspectos institucionais da inovação: uma análise acerca dos regimes automotivos brasileiros de 1995 a 2012. . In: ALTEC 2013: POLÍTICAS E GESTÃO DE CIÊNCIA E TECNOLOGIA NOS ESPAÇOS LATINO-IBEROAMERICANOS. Porto: ALTEC, 2013. 
PINTO, G. A. A máquina automotiva em suas partes: um estudo das estratégias do capital na indústria de autopeças. São Paulo: Boitempo, 2011.

PREBISCH, R. El desarrollo económico de la América Latina y algunos de sus principales problemas. Santiago: CEPAL, 2012. Disponível em:

<http://repositorio.cepal.org//handle/11362/40010>. Acesso em: 25 abr. 2017.

SAKURAMOTO, C. Y. Estratégia de operações: reposicionando a ferramentaria da General Motors do Brasil. Dissertação de mestrado - São Paulo: EAESP/FGV, 2002.

SCHAPIRO, M. G. O estado pastor e os incentivos tributários no setor automotivo. Brazilian Journal of Political Economy, v. 37, n. 2, p. 437-455, jun. 2017.

SHAPIRO, H. A primeira migração das montadoras: 1956-1968. In: ARBIX, G.; ZILBOVICIUS, M. (Eds.). . De JK a FHC: a reinvenção dos carros. São Paulo: Scritta, 1997. p. $23-87$.

SINDICATO DOS METALÚRGICOS DO ABC. Conheça o Inovar-Auto. São Bernardo do Campo, SP, abril de 2016. Disponível em: <https://www.youtube.com/watch?v=EB2j1XSwGVc>

TORRES, R. L. A indústria automobilística brasileira: uma análise da cadeia de valor. Dissertação de mestrado-Florianópolis: Universidade Federal de Santa Catarina, 2011.

VARGAS, T. B. A new player in the automotive public policies: the role of the tooling industry on Inovar-Auto. Who drives the change? New and traditional players in the global automotive sector. Anais... In: 26TH GERPISA INTERNATIONAL COLLOQUIUM 2018. São Paulo: Gerpisa, 2018. 